\title{
A constant error in the perception of brief temporal intervals*
}

\author{
JAMES C. CRAIG \\ Indiana Liniversity, Bloomington, Indiana
}

\begin{abstract}
Ss were presented two stimuli of equal duration separated in time. The pairs of stimuli were vibrotactile, auditory, or visual. The Ss adjusted the time between the two stimuli to be equal to the duration of the first stimulus. The results show that for stimulus durations ranging from 100 to $1,200 \mathrm{msec}$, Ss set the time between the two stimuli too long and by a constant amount. For vibrotactile stimuli, the constant was $596 \mathrm{msec}$; for auditory stimuli. $657 \mathrm{msec}$ : and for visual stimuli, $436 \mathrm{msec}$. Changing the intensity of the vibrotactile stimuli did not change the size of the constant error. When Ss were presented two tones with a burst of white noise between the tones and adjusted the duration of the white noise to be equal to the duration of the first tone, the white noise was not adjusted too long by a constant amount. The results suggest that there is a constant error in the perception of unfilled relative to filled temporal intervals.
\end{abstract}

In the course of exploring the possibility of utilizing the time between vibratory stimuli as a cue in a cutaneous communication system, Ss were presented with brief pairs of stimuli of equal duration. When the time between the two stimuli was equal to the duration of the stimuli, Ss reported that the time between felt much shorter than the duration of the stimuli. Such a result is consistent with a general statement that is often made in summarizing the literature on time perception, viz, "filled" intervals, time periods during which a stimulus is presented, are overestimated relative to "unfilled" intervals, time periods during which no stimuli are presented. Investigators have examined numerous stimulus and $S$ variables to determine their effect on the amount of overestimation that occurs or whether, indeed. any overestimation occurs at all (Fraisse, 1964: Woodrow, 1953). Because of these variables, it is difficult to predict with certainty the extent to which any particular stimulus might be overestimated. The present study was concerned with Ss' judgments of the time between vibratory stimuli, the effect of intensity changes on such judgments, and generality of the findings for other sense modalities, specifically vision and audition.

\section{EXPERIMENT I}

\section{Method}

\section{Subjects}

Two groups of Ss were used. The first group consisted of undergraduates who participated in the experiment to fulfill a requirement for an introductory psychology course. These $\mathrm{Ss}$ typically participated for two sessions lasting approximately $45 \mathrm{~min}$ each. The second group was made up of paid experienced undergraduate $S s$, who were tested repeatedly over a number of weeks. Neither group of $S s$ was given any information about

*This study was supported by Grant NS-09783 from the National Institutes of Health, U.S. Department of Health, Education and Welfare. The author wishes to express his appreciation to Ann Elsner for her assistance in data collection. their results or other $S s^{\prime}$ results until after the experiment was completed.

\section{Apparatus}

The apparatus consisted of equipment to generate vibrotactile stimuli and programming equipment to control the presentation of the stimuli. The output of a Hewlett-Packard 200AB oscillator was gated by a Grason-Stadler $829 \mathrm{C}$ electronic switch with a rise time of $10 \mathrm{msec}$. The output of the electronic switch was attenuated, amplified, and led to a Goodmans V-47 vibrator. which rested on the weighing pan of a balance. Sufficient weights were added to offset the weight of the vibrator. An additional $20 \mathrm{~g}$ of weight were added to the balance to insure firm contact between the S's finger and the contactor of the vibrator. The circular contactor was $6 \mathrm{~mm}$ in diam and protruded through a fixed, circular surround, $8 \mathrm{~mm}$ in diam.

The stimuli were programmed by the output of a Tektronix 162 waveform generator with a waveform duration of $5 \mathrm{sec}$. The waveform generator triggered two Tektronix 161 pulse generators, which in turn drove a relay. Closing the relay triggered the electronic switch that turned on and off the vibrotactile stimuli. Varying the pulse width of the pulse generators changed the duration of the stimuli. By means of a potentiometer connected to the output pulse delay of one of the pulse generators, the $\mathrm{S}$ could change the time between the pulses produced by the pulse generators and thus adjust the time between two vibrotactile stimuli. The potentiometer was fitted with a plain black knob. The time between the offset of the first stimulus and the onset of the second stimulus was measured by a General Radio 1192 counter.

\section{Procedure}

The Ss were seated at a table with their right arms extended. The right index finger was placed over the fixed surround and the vibrator brought in contact with the finger. Instructions informed the $S$ s that they would receive two bursts of vibration of equal duration separated by a time interval. By turning the knob in front of them, they could adjust the time between the two bursts. Their task was to adjust the time between the bursts of vibration until they were satisfied that it appeared equal in duration to the duration of the first burst. They were encouraged to use a bracketing technique to arrive at their final estimate. After making their adjustments. they were told that the duration of the two stimuli would be changed and another trial would be run. Ss were given two practice trials and asked if there were any questions before the experiment began. The trials were self-paced. Approximately 1.2 sec elapsed between the time the $S$ pushed a button to start the trial and the onset of the first 


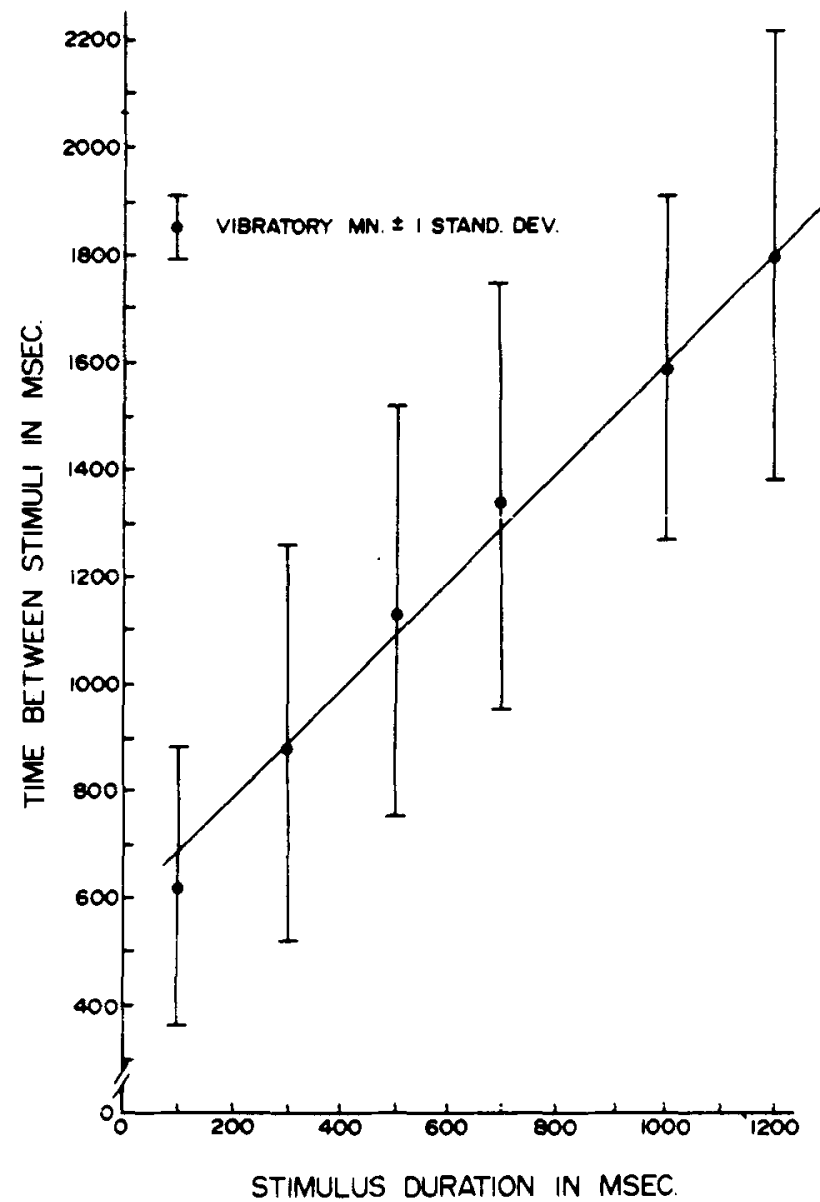

Fig. 1. The time between two vibrotactile stimuli of equal duration adjusted by $S s$ to be equal to the duration of the first stimulus as a function of the duration of the first stimulus. The results are based on the settings from 16 Ss. A line with a slope of 1 has been drawn for comparison purposes.

stimulus. Throughout the experimental session, Ss wore earphones through which white noise was fed to mask any sounds the equipment might make. Each $\mathrm{S}$ was run individually.

The vibrotactile stimulus was $160 \mathrm{~Hz}$ at a coil voltage of $160 \mathrm{mV}$ peak to peak, which produces a contactor amplitude approximately $30 \mathrm{~dB}$ above threshold for a $200-\mathrm{msec}$ stimulus. A series of pairs of stimuli of equal duration, with each member of the pair $100,300,500,700,1,000$, or $1,200 \mathrm{msec}$ in duration, was presented to the Ss. The stimuli were presented in random order with the constraint that all six pairs of stimuli were presented before a second series of six was run. On the average, Ss completed two series of six stimuli in each of the two experimental sessions. Prior to each experimental session, Ss received practice trials using $600-$ and $800-\mathrm{msec}$ stimulus durations. Three experienced $S s$, who received the same instructions as the naive Ss, were also tested on this series of stimuli.

\section{Results}

The results for the 3 experienced and 13 naive $S$ s are shown in Fig. 1. The experienced Ss were tested to see if repeated presentations of the stimuli would tend to diminish the observed effect. Because the experienced Ss showed the same effect as the naive Ss throughout the course of the experiment, their results have been grouped with the naive Ss' results. Each point represents the mean of a total of 92 observations. Each of the experienced $\mathrm{Ss}$ in Experiments I and III made 15 settings for each of the six durations. The standard deviations shown in Fig. 1 are based on the total number of individual settings by all Ss. The mean amount by which the unfilled interval was set too long relative to the filled interval was $596 \mathrm{msec}$. A line with a slope of 1 and an intercept of 596 has been drawn through the data points for the purpose of comparison.

Several things about these data are clear. First, Ss set the unfilled intervals much longer than the filled intervals. It is not possible to state whether the filled interval was overestimated or the unfilled interval underestimated, inasmuch as the Ss were making a relative judgment. Second. unlike many other results from time estimation studies, the present results do not show a constant percent overestimation or underestimation but rather a constant amount by which the unfilled interval differs from the filled interval. That is, for any duration of a filled interval, the Ss set the unfilled interval at that duration plus $596 \mathrm{msec}$. Two $300-\mathrm{msec}$ filled intervals resulted in the S's setting the unfilled interval at $300 \mathrm{msec}$ plus approximately $596 \mathrm{msec}$, i.e. $896 \mathrm{msec}$. It should be noted that the task in this experiment is somewhat different fiom tasks used in other time estimation studies. Some of the differences among tasks are currently being examined to determine what factors may be responsible for the differences in results. Third, it appears that Ss were responding appropriately to changes in the duration of the filled interval. If the duration of the filled interval was increased $200 \mathrm{msec}$, e.g., from 300 to $500 \mathrm{msec}$, the Ss changed their settings of the unfilled interval by $200 \mathrm{msec}$, from 896 to $1,096 \mathrm{msec}$. This result is reflected in the close fit of the data points to a line with a slope of 1 .

\section{EXPERIMENT II}

Many studies on time estimation have reported that changes in the stimuli bounding an unfilled time interval result in changes of the perceived duration of the unfilled interval (Fraisse, 1964; Woodrow, 1953). One likely variable for manipulation with vibrotactile stimuli is intensity. Bekésy (1967) has pointed out that the perceived magnitude of a vibrotactile stimulus increases as a function of its duration. Increasing the duration from 300 to $1,200 \mathrm{msec}$ resulted in an increase of perceived magnitude of $6 \mathrm{~dB}$ measured relative to its maximum perceived magnitude (Békésy, 1967). In Experiment I, in which the amplitude of vibration was held constant, changes in the duration of stimuli might have resulted in changes in the perceived magnitude. It is possible that the change in the perceived magnitude 
could be used by Ss as a cue to change accordingly their adjustments of the unfilled interval. Experiment II was designed to test the effect of changing the intensity of vibrotactile stimuli on time estimations of the unfilled interval.

\section{Method}

\section{Subjects}

The three experienced Ss from Experiment I were used.

\section{Apporatus}

The apparatus was the same as in Experiment I.

\section{Procedure}

The procedure was similar to the procedure in Experiment 1 . Four durations were selected for testing-100, 300,700, and $1,000 \mathrm{msec}$. Each pair of stimuli was presented at one of four intensity levels $-90,160,290$, and $510 \mathrm{mV}$ peak to peak. These voltages cover a range of intensity of $15 \mathrm{~dB}$. There were four intensity levels presented at four durations for a total of 16 different pairs of stimuli. The stimuli were presented in random order, the only constraint being that no stimulus pair was repeated until all 16 stimulus pairs had been presented.

\section{Results}

The results are shown in Table 1. Each value represents the mean of 24 observations. The results show that changing the intensity of the stimuli had no consistent effect on Ss' judgments of the unfilled interval. The mean amount across durations by which Ss set the unfilled intervals too long was $650 \mathrm{msec}$ at $90 \mathrm{mV}, 634 \mathrm{msec}$ at $160 \mathrm{mV}, 645 \mathrm{msec}$ at $290 \mathrm{mV}$, and $640 \mathrm{msec}$ at $510 \mathrm{mV}$. It appears that the judgments of duration were independent of the intensity of the stimuli. As in Experiment I, the results indicate that Ss set the unfilled interval longer than the filled interval by a constant amount.

\section{EXPERIMENT III}

The purpose of Experiment III was to determine whether the results obtained in Experiments $I$ and II were confined to the somesthetic system and vibratory stimuli. Experiment III used stimuli in two other modalities.

\section{Method}

\section{Subjects}

As in Experiment $I$, the same group of experienced $S$ s and a different group of naive $S s$ were tested. The naive $S s$ participated in either the auditory or visual portion of the experiment, but not in both. Neither group of Ss was given any feedback.

\section{Apparatus}

To generate the visual stimuli. a glow-modulator tube, Sylvania $R 1131 \mathrm{C}$. was energized with $135 \mathrm{dc}$. The tube was
Table 1

Settings of Unfilled Intervals in Milliseconds as a Function of Stimulus Intensity and Duration

\begin{tabular}{ccccc}
\hline $\begin{array}{c}\text { Stimulus } \\
\text { Intensity } \\
(\mathrm{mV})\end{array}$ & \multicolumn{4}{c}{ Stimulus Duration in $\mathrm{M} \mathrm{sec}$} \\
\cline { 2 - 5 } & 100 & 300 & 700 & 1000 \\
\hline 90 & 622 & 1040 & 1451 & 1589 \\
160 & 647 & 984 & 1449 & 1558 \\
290 & 641 & 962 & 1422 & 1655 \\
510 & 672 & 928 & 1405 & 1654 \\
\hline
\end{tabular}

placed behind a screen with a ${ }^{1}$-in.-diam hole. A semitransparent piece of white paper was placed over the hole to reduce the intensity of the light and diffuse it. The light flash, $13.00 \mathrm{fc}$, was superimposed on a fixation light, $0.29 \mathrm{fc}$.

To generate the auditory stimulus, a $1,000-\mathrm{Hz}$ tone was switched by a Grason-Stadler electronic switch with a rise time of $10 \mathrm{msec}$. The signal was led to TDH-39 earphones, $600 \mathrm{ohms}$ connected in series. The voltage across the phones was $100 \mathrm{mV}$ peak to peak. The programming and timing of stimuli was controlled in the same way as in Experiments I and II.

\section{Procedure}

For the visual stimuli, the Ss were seated approximately 30 in. from the light source. The room was illuminated with subdued light. The durations used and the procedure were the same as in Experiment I.

\section{Results}

The results for both naive and experienced Ss have been combined in Fig. 2. The standard deviations shown in Fig. 2 are based on the total number of individual settings by all Ss. For the auditory stimuli, each point represents the mean of a total of 120 observations obtained from 8 naive and the 3 experienced Ss. For the visual stimuli, each point represents the mean of a total of 127 observations obtained from 11 naive and the 3 experienced Ss. For both the auditory and visual stimuli, the experienced $S s$ continued to set the unfilled interval too long by a constant amount, indicating that the observed effect did not disappear with repeated trials. Although the experienced $S s$ set the unfilled intervals shorter in the visual condition than in the auditory condition, they did set the unfilled intervals in the visual condition longer than did the naive Ss. The larger settings by the experienced Ss may be a result of their previous exposure to the vibrotactile and auditory stimuli. The largest differences between the experienced and naive $S s$ were seen at the longer durations, 1,000 and $1,200 \mathrm{msec}$, where several of the naive Ss did not set the unfilled interval longer than the filled interval. This failure to set the unfilled interval too long occurred only with visual stimuli and only at the longer durations. The mean amount by which the unfilled interval was set too long relative to the filled interval for the auditory stimuli was $657 \mathrm{msec}$; for the visual stimuli, it was $436 \mathrm{msec}$. A line with a slope of 1 and an intercept of 657 for the auditory stimuli and a line with a slope of 1 and an 


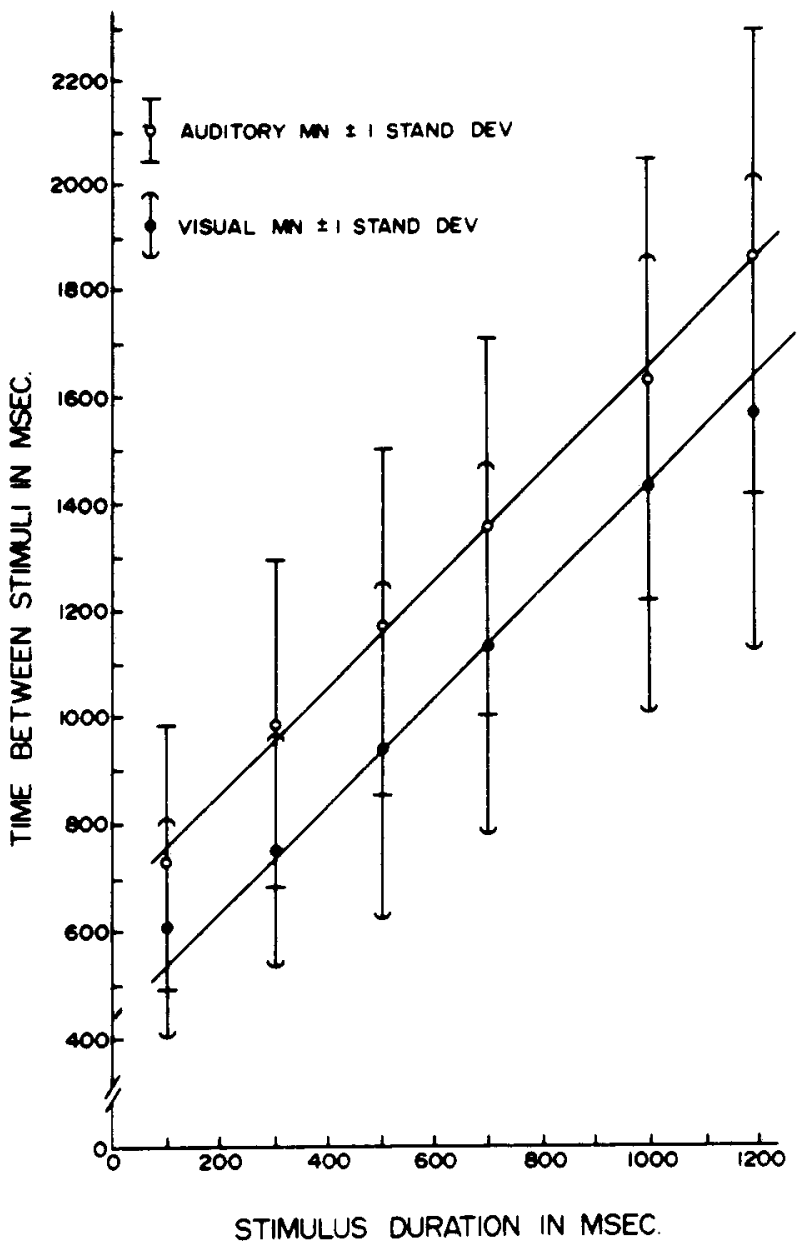

Fig. 2. The time between stimuli of equal duration adjusted by $\mathrm{Ss}$ to be equal to the duration of the first stimulus as a function of the duration of the first stimulus. The parameter is sensory modality. The auditory results are based on the settings from 11 Ss. The visual results are based on the settings from 14 Ss. Lines with slopes of 1 have been drawn for comparison purposes.

intercept of 436 for the visual stimuli have been drawn through the data points.

A Scheffé post hoc comparison test performed on the vibrotactile, auditory, and visual data did not show any significant differences as a function of the modality in which the stimuli were presented. The overall similarity of the results obtained with auditory, visual, and vibrotactile stimuli indicates that the phenomenon of setting the unfilled interval much too long relative to the filled interval and by a constant amount is not limited to the cutaneous modality.

\section{EXPERIMENT IV}

The results from Experiments I, II, and III have been discussed in terms of a comparison of filled to unfilled time intervals. However, it is possible that the setting of the unfilled interval too long by a constant amount is not dependent upon some property of filled or unfilled intervals but rather upon the pattern of stimulus events, i.e., one temporal interval bounded by two other intervals. Experiment IV was designed to test whether the effect observed in Experiments I, II, and III was dependent upon the middle interval being an unfilled interval or whether the same effect would be obtained if a stimulus replaced the unfilled interval. Specifically, if Ss were presented two tones separated by a burst of white noise and instructed to adjust the duration of the noise to be equal to the duration of the first tone, would Ss set the duration of the noise too long by a constant amount?

\section{Method}

\section{Subjects}

The Ss were paid undergraduate volunteers tested as described in Experiment I. Each of the 12 Ss tested made six adjustments at each of the six durations. None of the $S$ s had participated in any of the previous experiments.

\section{Apparatus}

The apparatus used to generate auditory stimuli in Experiment III was modified so that a burst of white noise from a Grason-Stadler noise generator replaced the unfilled interval. The voltage across the earphones for the white noise was $200 \mathrm{mV}$ rms. The intensity of the tones was the same as in Experiment III. The white noise and tones were judged to be approximately equal in perceived magnitude.

\section{Procedure}

The Ss were instructed that they would receive two tones of equal duration with a burst of noise between the tones. They were to adjust the duration of the noise to be equal to the duration of the first tone. The durations used and the procedure were the same as in Experiments 1 and III.

\section{Results}

The results are presented in Fig. 3. Each point represents the mean of 72 observations. The standard deviations shown in Fig. 3 are based on the total number of individual settings by all Ss. A line with a slope of 1 and an intercept of 0 has been drawn for purposes of comparison. A Mann-Whitney $U$ test showed that there was a significant difference between the adjustments made by Ss with auditory stimuli in Experiments III and IV.

Unlike the results from Experiments I, II, and III, Ss did not set the duration of the middle interval too long by a large, constant amount. The mean amount by which the Ss set the white noise too long relative to the tone was $6 \mathrm{msec}$. The only difference between Experiment IV and the auditory condition in Experiment III was the presence of a stimulus to fill the middle interval. The fact that filling the middle interval results in no significant error in the setting of the middle 
interval strongly suggests that the effect observed in Experiment III with auditory stimuli is the result of the comparison between filled and unfilled temporal intervals. In addition, some preliminary data collected with vibratory stimuli comparing two filled intervals indicate that the effect observed in Experiments I and II is also the result of the comparison between filled and unfilled intervals. Additional work would be necessary to determine if any combination of stimuli, e.g., tone-light-tone, would lead to a similar decrease in the observed effect. The decrease in variability of 'Ss' responses in Experiment IV as compared to Experiment III may reflect a greater ease in judging filled as opposed to unfilled time intervals.

\section{DISCUSSION}

How could the large constant errors in the setting of the unfilled interval be explained? The results could be accounted for if some representation of the stimulus lasted beyond the offset of the stimulus. Such a representation would have to be very similar to, if not indistinguishable from, the representation of the physical stimulus. The absence of error when the middle interval is filled, as in Experiment IV, might be explained by assuming that the onset of the second stimulus terminated the representation of the first stimulus. Efron (1970) has reported that brief stimuli, either visual or auditory, produced a delayed perceptual offset. However, the effect holds only for very brief stimuli, of less than approximately $150 \mathrm{msec}$ in duration, and could not be stretched to cover the errors in the range of 400 to $650 \mathrm{msec}$ found in the present study. Moreover, under the experimental conditions in the present study, Ss reported little difficulty in detecting a discontinuity, an unfilled interval, greater than $30-50 \mathrm{msec}$. This result held whether vibrotactile, auditory, or visual stimuli were used. It is unlikely that the large errors in the setting of the unfilled interval could be accounted for by some lingering representation of the first stimulus after its offset that the Ss confused with the stimulus itself.

Fraisse (1964) has cited some early work on the presentation of two stimuli with a brief temporal gap between them. Ss report that if the gap between two stimuli is less than $600 \mathrm{msec}$, Ss tend to perceive "... an integrated pair of stimuli (Schultze, 1908). Thus we do not spontaneously perceive a gap. We perceive two more or less closély linked stimuli.... When the gap between stimuli reaches about $0.6 \mathrm{sec}$, we have a spontaneous perception of an interval, but this is not dissociable from its limits [Fraisse, 1964, p. 117]." Fraisse also points out that if $S s$ are asked to reproduce an auditory stimulus, they begin to react about $700 \mathrm{msec}$ after the offset of the stimulus (Oleron, 1952). On the basis of these results, he suggests that there is some perceptual timing process which lasts between 500 and $700 \mathrm{msec}$ after the offset of a stimulus. In the present study, the

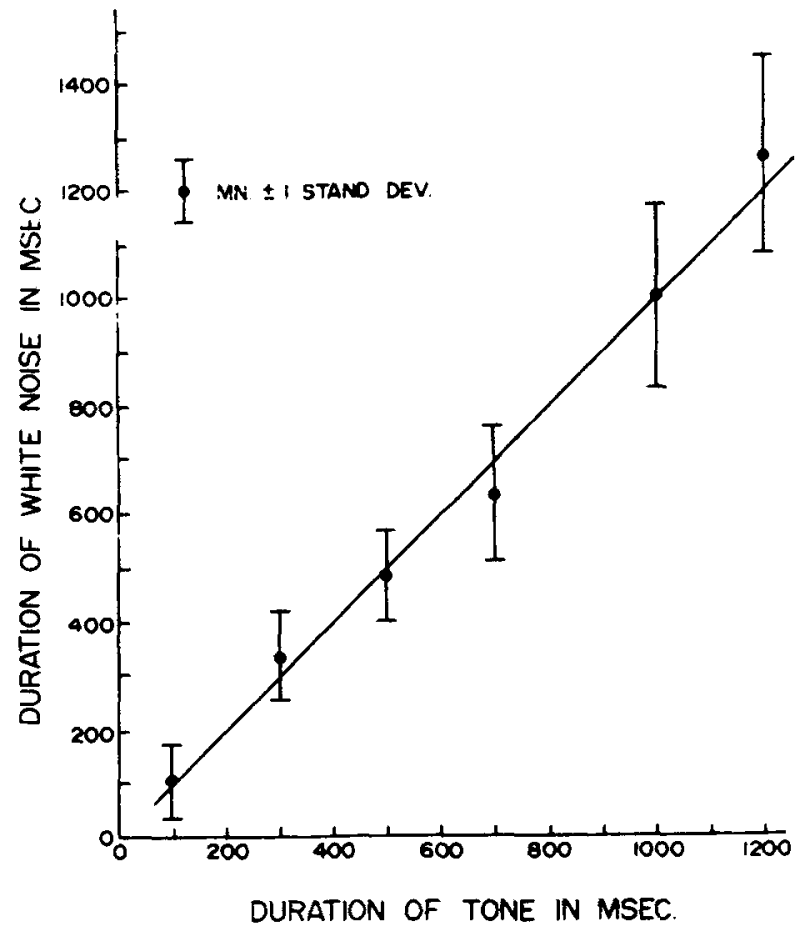

Fig. 3. The duration of white noise adjusted by $S$ s to be equal to the duration of the first of a pair of tones of equal duration as a function of the duration of the first tone. The white noise was interposed between the two tones. The results are based on the settings from 12 Ss. A line with a slope of 1 has been drawn for comparison purposes.

offset of the first stimulus is the cue which not only signals the end of the stimulus but also the beginning of the unfilled interval. If switching from timing the duration of the stimulus to timing the duration of the unfilled interval requires a perceptual timing process that lasts between 500 and $700 \mathrm{msec}$, then the present results are consistent with the notion of such a process. However, it is not clear why switching from timing the duration of a tone to timing the duration of a white noise should not also require a similar perceptual timing process.

It would seem that the explanation for the effect observed in these experiments revolves around some fundamental difference in the timing mechanisms required for filled and unfilled intervals. The nature of these mechanisms is not known. The present study obviously raises a number of questions to be answered by further research. The answers to these questions may provide information about the generality of the present results and the implications of the results for a number of human activities involving the perception of brief time intervals.

\section{REFERENCES}

Békésy, G. von. Sensory inhibition. Princeton, N.J: Princeton University Press, 1967. 
Efron. R. Fffect of stimulus duration on perceptual onset and offset latencies. Perception \& Psychophỵsics. 1970. 8. $231-234$.

Fraisse. P. The psichologi of time. London: Eytre \& Spottiswood. 1964.

Oleron. G. Influence de lintensité dun son sur lestimation de sa durèe apparente. Année psichologie. 1952. 52. 383-392. Cited by P. Fraisse. The psichology of time. London: Fyre \& Spottiswood. 1964.
Schultze, O. Beitrag zur Psychologie des Zeitbewussteins. Archiv fur die gesamte Psychologie. 1908. 13, 275-351.

Woodrow. H. Time perception. In S. S. Stevens (Ed.), Handbook of experimental psychologr. New York: Wiley, 1953. Pp. 1224-1236.

(Received for publication June 30. 1972: revision received September 2. 1972.) 